\section{Estudo \\ cabebate}

em Testão

Plamejamento
Revista Estudo \& Debate, Lajeado, v. 25, n. 2, 2018. ISSN 1983-036X

DOI: http://dx.doi.org/10.22410/issn.1983-036X.v25i2a2018.1584

\title{
ANÁLISE ESTRUTURAL DO MERCADO BRASILEIRO DE PICAPES PEQUENAS
}

\author{
Gabriel de Paula Eduardoํㅡㄹ Adelson Martins Figueiredo ${ }^{2}$, Mariusa Momenti Pitelli ${ }^{3}$
}

\begin{abstract}
Resumo: A venda de picapes pequenas no Brasil é altamente concentrada em quatro empresas, em que a Fiat tende a ter a maior participação de mercado, em termos de unidades vendidas. Assim, o objetivo desta pesquisa foi testar a ocorrência de exercício de poder de mercado no segmento de picapes pequenas. O referencial teórico teve como base a teoria da New Empirical Industrial Organization (NEIO) e aplicou-se o modelo econométrico baseado em Berry et al. (1995), um modelo estrutural de demanda e oferta para estimação do equilíbrio de mercado, onde aplica-se um modelo randômico de utilidade para derivar a demanda e assume-se que o logaritmo do custo marginal é linear em relaçáo ao custo dos atributos. Os resultados mostram que o markup médio ponderado do segmento é de cerca $12 \%$ e que a estratégia de competição das firmas oscila ao longo do tempo. Portanto, foi possível rejeitar a hipótese nula de que os modelos de competição de Bertrand e de cooperaçáo são indistinguíveis em favor da cooperação em alguns subperíodos.
\end{abstract}

Palavras-chave: Poder de mercado. Estratégia Competitiva. Markup. Setor automobilístico.

\section{STRUCTURAL ANALYSIS OF THE BRASILIAN MARKET OF SMALL PICKUP TRUCKS}

\begin{abstract}
Market of small pickup trucks in Brazil is highly concentrated in four firms, which Fiat has been keeping the largest market share, in terms of total sales. The purpose of this research is to test the possibility of use market power by these firms. The New Empirical Industrial Organization is the main theory that supports this study and it has been applied a structural econometric model based on Barry (1994) to estimate the market equilibrium. The results have shown that the mean weighted markup is around $12 \%$ and the competitive strategy of firms change over time. Therefore, it has been rejected null hypothesis of Bertrand competition model and of cooperation model are indistinguishable in favor of the cooperation in sub-periods of time.
\end{abstract}

Keywords: Market power. Competitive strategy. Markup. Automotive sector.

1 Mestre em Economia pela Universidade Federal de São Carlos.

2 Doutor em Economia Aplicada pela Universidade Federal de Viçosa, Professor da Universidade Federal de São Carlos.

3 Doutora em Economia Aplicada pela Universidade de São Paulo, Professora da Universidade Federal de São Carlos. 


\section{INTRODUÇÁO}

O setor automotivo brasileiro é caracterizado pela concorrência de poucas empresas com alto volume de capital e que fabricam uma elevada gama de produtos diferenciados, assemelhando-se à estrutura de mercado oligopolista concentrado e diferenciado (FARIAS, 2009; MATTOS e BARROS, 2006). Este oligopólio global de multinacionais é suportado por barreiras econômicas e tecnológicas à entrada de novos competidores. Olhando especificamente para o mercado brasileiro, também se identificam barreiras à entrada para a importação, favorecendo empresas com processos produtivos instalados em território nacional.

Baseando-se na teoria da organização industrial - descrita, por exemplo, em Church e Ware (2000) - deduz-se que a alta concentração e as barreiras à entrada observadas no setor automotivo brasileiro podem possibilitar o uso de poder de mercado, resultando em menor bem-estar social.

De acordo com Church e Ware (2000), a barreira à entrada, característica estrutural de um mercado, possibilita a manutenção do poder de mercado das firmas estabelecidas, uma vez que torna a entrada não lucrativa. A extensão do poder de mercado de uma firma, no longo prazo, depende da elasticidade de sua curva de demanda. Entrada e competição de outros produtos e outros produtores limitam o poder de mercado das firmas se as barreiras à entrada não são significantes.

Ainda segundo os autores, a preservação do poder de mercado e lucros monopolísticos dependem também do comportamento das firmas estabelecidas após a entrada, uma vez que podem agir de forma agressiva no mercado e fazer investimentos para criar ou aumentar as barreiras à entrada.

A rivalidade efetiva entre as firmas estabelecidas em um mercado irá dificultar o exercício do poder de mercado (BRASIL, 2016). Assim, a conduta das firmas em um determinado mercado - se irão rivalizar ou fazer cooperação (tácita ou explícita) - afeta a possibilidade do uso desse poder.

Ressalta-se que o exercício de poder de mercado prejudica a livre concorrência, causando perdas para o consumidor, como por exemplo, por meio da fixação de maiores preços e da oferta de produtos de menor qualidade.

Os altos preços dos veículos brasileiros comparados com os de outros países (EXAME, 2013; GLOBO, 2009) instigam debates relacionados à existência do exercício de poder de mercado na indústria automobilística nacional.

Relacionado a isso, em dezembro de 2012, ocorreu uma audiência pública dirigida pela Comissão de Assuntos Econômicos do Senado para discutir os altos preços dos carros no Brasil. Para ilustrar o tema, um exemplo discutido foi o do Toyota Corolla, visto que o carro custa US\$ 16,2 mil nos Estados Unidos, US\$ 21,6 mil na Argentina e US\$ 28,6 mil no Brasil (BRASIL, 2012).

O mesmo estudo revela que o custo de produção no Brasil é de $58 \%$ do preço final do carro, contra a média mundial de $79 \%$ e que chega a ser de $91 \%$ nos EUA. Também indica que o lucro no Brasil chega a ser três vezes maior que em outros países, visto que a 
margem praticada no Brasil é uma das maiores do mundo, $10 \%$ sobre o valor ao consumidor, enquanto a margem média mundial é de $5 \%$ e nos Estados Unidos o lucro é de 3\%. No Brasil, a carga tributária sobre o carro é da ordem de 32\%, a média mundial está perto de $16 \%$ e nos Estados Unidos varia em torno de 7\%. A alta margem no Brasil eleva o interesse de novas firmas entrarem no mercado sem refletir apenas a tendência de expansão desse mercado (BRASIL, 2012).

O exercício de poder de mercado na indústria automobilística brasileira foi estudado inicialmente por Negri (1998) de forma a identificar o custo de bem-estar proporcionado pelo regime automotivo da década de 90. Por meio do cálculo da elasticidade-preço da demanda, encontrou-se uma demanda de veículos preço-inelástica, na sequência estimou a trajetória futura dos preços em função das observações anteriores e posteriores ao regime automotivo, o que indicou uma diferença que resulta na perda de bem-estar social.

Farias (2009) indica que seguindo as definiçóes de Shepherd (1997), o mercado automobilístico no Brasil em 2007 é considerado um oligopólio forte visto que a concentração das quatro maiores empresas de $84 \%$ é maior que $60 \%$ e que o índice Hirschman-Herfindahl de 0,20 é superior a 0,18 . Ainda, o Guia de Análise de Concentração Horizontal da Secretaria de Acompanhamento Econômico do Ministério da Fazenda (BRASIL, 2016) considera que uma concentração das quatro maiores empresas superior a $75 \%$ viabiliza a possibilidade do uso de poder de mercado coordenado. Além disto, Farias (2009) utiliza um modelo que estima para diversas versóes de carros, de forma conjunta, um sistema de equaçóes de demanda e de funçóes de reação de preço. Os resultados do estudo evidenciam a existência de poder de mercado no oligopólio diferenciado no segmento de picapes pequenas.

Neste ponto, vale destacar a importância do setor automobilístico para a economia brasileira. No Brasil, optou-se preferencialmente pelo modal rodoviário que, aliado com a baixa qualidade dos meios de transportes públicos, propicia a necessidade de obtençáo desse bem e resulta no quarto maior mercado automotivo do mundo (CASOTTI; GOLDENSTEIN, 2008). O setor automotivo é responsável por aproximadamente $25 \%$ do PIB industrial e tem fortes ligaçóes com outros setores da economia: siderúrgico, borracha e vidro; além disso, o setor é forte gerador de empregos. Desta forma, a indústria tem caráter estratégico, considerando os impactos econômicos e tecnológicos, as oportunidades de desenvolvimento e qualificação do setor industrial do país, além de favorecer vários outros segmentos produtivos ligados a esta indústria; e por todo o descrito, tem sido alvo de políticas públicas nos anos recentes.

A identificação do mercado relevante é importante nos estudos de exercício de poder de mercado (SOUZA et al., 2010; FARIAS, 2009). A delimitação do mercado relevante é tratada em duas dimensôes: produto e geográfica. A dimensão do produto define os bens substitutos comercializados. Para a pesquisa, os veículos automotores novos do tipo picapes pequenas tal como segmentado pela FENABRAVE (2014) e ANFAVEA (2014) foram considerados como um mercado relevante. Ressalta-se que as picapes pequenas compóem atributos únicos como funcionalidade em transporte de carga e pessoas, capacidade de carga e dimensóes; que as definem adequadamente e as distinguem dos demais bens. Ademais, o mercado de veículos usados não faz parte do escopo deste estudo e a faixa de preço não foi considerada como restrição. Na dimensão geográfica, o mercado relevante foi definido como 
sendo o território nacional, visto que as montadoras que atuam no segmento (Fiat, VW, GM, Ford e PSA) possuem concessionárias com abrangência em todo território nacional.

O segmento de picapes pequenas é um dos mais concentrados no mercado automotivo brasileiro, sendo este um dos motivos de seleção do mesmo para o estudo. Este produto, considerado bem de capital, se caracteriza pela funcionalidade, sendo utilizado para transporte de carga por firmas. O período de estudo compreende janeiro de 2001 a maio de 2014. As únicas firmas que participaram deste segmento no período de estudo foram a Fiat, a Volkswagem (VW), a Chevrolet (General Motors - GM), a Ford e a Peugeot (Peugeot Société Anonyme - PSA) com seus respectivos produtos: Strada, Saveiro, Montana, Courrier e Hoggar.

Conforme dados da FENABRAVE (2014) e ANFAVEA (2014) referentes a parcela de mercado sobre as quantidades vendidas das montadoras brasileiras de automóvel, no período de 2001 a 2014 a Fiat, em média, tem a maior participação do mercado de picapes pequenas, em torno de $50 \%$ no período. A Volksvagem transitou por condiçóes distintas ao longo dos anos, compartilhando no início grande parte do mercado e após a entrada da GM no segmento, disputou a segunda posição com a mesma até os anos mais recentes onde estabilizou ao redor de 30\%. A GM iniciou as atividades em 2004 obtendo grande sucesso no lançamento e oscilou ao redor de $20 \%$ em média no período.

A Ford foi continuamente perdendo participação no período estudado, até retirar o produto do segmento em 2013, mostrando como a diferenciação do produto é importante. A PSA tentou entrar no segmento em 2010, mas não obteve sucesso e também encerrou as atividades, indicando o reflexo das barreiras à entrada. A empresa entrou no mercado e não conseguiu rivalizar, ressaltando a importância da diferenciação do produto, uma vez que diminui a substituição entre os produtos e, portanto, a concorrência entre eles.

O objetivo desta pesquisa foi verificar se há ocorrência do exercício de poder de mercado no segmento de picapes pequenas do setor de automóveis no Brasil, no período de janeiro de 2001 a maio de 2014. Como objetivo específico, pretendeu-se analisar os parâmetros de demanda e de custos para cada versão de picapes pequenas comercializadas no Brasil e analisar diferentes conjecturas de comportamento estratégico das firmas para determinar o nível de competitividade do mercado. Testou-se a hipótese de que há prática de exercício de poder de mercado no segmento de picapes pequenas no mercado automotivo brasileiro.

\section{REFERENCIAL TEÓRICO}

A abordagem da Escola de Chicago que surge na década de 1980, como sumarizado em Bresnahan (1989) e Hyde e Perloff (1995), embasada na teoria de jogos aplicada aos mercados oligopolistas, é conhecida por 'Empirical Industrial Organization', que está associado ao trabalho empírico NEIO.

Fundamentada em conceitos teóricos para ponderar a formação de preços e seu relacionamento com o uso de poder de mercado, a teoria NEIO versa a motivação do comportamento das firmas no mercado com base em dados quantitativos de preço e quantidade, permitindo analisar a competitividade de mercado. Esta teoria foi primeiramente 
aplicada por Appelbaum (1979), Gollop e Roberts (1979), Just e Chern (1980) e Bresnahan (1981). No entanto, Bresnahan (1982) e Lau (1982) foram os primeiros a generalizar a formulação de identificação do poder de mercado. Diferentes abordagens da metodologia foram inicialmente sumarizadas por Bresnahan (1989), sendo o entorno destes trabalhos a modelagem econométrica para identificar comportamentos oligopolistas usando dados de preço e quantidade.

A análise da conduta, fundamentada nos modelos de Teoria dos Jogos, é realizada com base no comportamento implícito das firmas que é observado nas condiçóes de equilíbrio do mercado, tendo diferentes modelos para mercados de bens homogêneos e diferenciados. A abordagem NEIO trabalha assumindo que os custos marginais não são observáveis e provavelmente não estimáveis e; que o comportamento de cada setor é único de tal forma que as condutas individuais das firmas e do setor são parâmetros a serem estimados (BRESNAHAN, 1989). Desta forma, esta abordagem faz uso de modelos estruturais que descrevem teoricamente como firmas se comportam com diferentes estruturas de mercado. Referências dos métodos empíricos podem ser encontradas nos trabalhos Bresnahan (1989), Martin (2002) e mais recentemente em Boone (2007). Assim, estima-se um modelo estrutural com equaçóes de comportamento, demanda e oferta usando séries temporais de preço, quantidade, vários outros custos de recursos e vários outros parâmetros que influenciam demanda e oferta.

A teoria NEIO é suportada pela modelagem econométrica; a solução econométrica do modelo de Bresnahan (1982) utiliza equaçóes simultâneas de demanda e oferta para identificar no equilíbrio a quantidade e o preço de cada bem. Neste sentido, Bresnahan (1989) generaliza que uma aplicação NEIO é um modelo econométrico de um mercado. Um dos primeiros trabalhos, realizado por Just e Chern (1980), analisa o poder de oligopólio no setor de processamento de tomate.

Os primeiros modelos eram estáticos de um oligopólio não-cooperativo e simétrico, os desenvolvidos por Cournot e Bertrand estáo dentre os primeiros aplicados (BRESNAHAN, 1989). O trabalho de Bresnahan (1981) é um exemplo de utilização deste tipo de abordagem aplicado ao mercado de automóveis, onde a diferenciação do bem está compreendida num espaço unidimensional. A demanda por um automóvel é determinada pelo preço e qualidade, sendo esta descrita por uma função hedônica que contém atributos tal como: massa, dimensóes, capacidades e desempenho. Dentre os resultados de Bresnahan (1981), identificou-se que veículos de dimensôes maiores possuem uma margem maior entre o preço e o custo e, que tais veículos também estão mais diferenciados em relação a qualidade unidimensional.

Outros estudos utilizam uma abordagem dinâmica, aplicando interaçóes repetidas em oligopólios, tentando verificar o efeito de curto e longo prazo no poder de mercado, como é o caso de Porter (1983), Abreu (1986) e Rotemberg e Saloner (1986). De forma geral, existem diferentes consideraçóes nas modelagens para caracterizar a mudança de um regime para o outro, bem como diferentes expectativas de comportamento para cada regime.

Dentro das aplicaçóes da modelagem dinâmica, é interessante ressaltar o trabalho de Steen e Salvanes (1999) que parte da modelagem de Bresnahan (1982) e trata de forma simplificada o fenômeno dinâmico, fazendo uso de correção de erros para equilíbrio de 
longo prazo. Devido à necessidade de hipóteses explícitas nas equações do modelo e de vasta quantidade de dados, surgiu o método de forma reduzida desenvolvido por Hall (1996) e Panzar e Rosse (1987).

Uma das primeiras aplicaçóes é o trabalho de Hyde e Perloff (1995) que analisa a modelagem estrutural proposta na aferição de poder de mercado. As conclusões do trabalho de Hyde e Perloff (1995) indicam que a modelagem é funcional e pode apresentar bons resultados se devidamente especificada, no entanto, o modelo de Hall se adequa apenas com condiçôes ideais. A grande maioria destes trabalhos trata de bens homogêneos e caracteriza o poder de mercado de todas as firmas conjuntamente, sem considerar as individualidades. Assim, modelos de equilíbrio de um oligopólio para bens diferenciados são utilizados para identificar atributos de demanda e oferta, permitindo testes de hipóteses referentes ao nível de poder de mercado.

Neste contexto, surge o trabalho de Bresnahan (1987), onde se tenta explicar a guerra de preço no mercado automotivo dos Estados Unidos no ano de 1955. O autor busca por meio da teoria NEIO explicar os movimentos na quantidade total e nos preços que indicam um choque de oferta. No ano de 1955 a quantidade de carros vendidos foi alta e os preços foram baixos quando comparados com os anos anterior e posterior. Bresnahan (1987) utiliza um modelo de demanda baseado na escolha discreta individual de comprar ou não o carro, além disso, o modelo apresenta diferenciação vertical unidimensional definida pela qualidade. A qualidade é definida com base em atributos observáveis do carro como dimensôes, potência do motor, funcionalidades e conteúdo específicos. O consumidor tem diferente propensão marginal a pagar por qualidade, assim, escolhe o carro que minimiza a relação entre o preço e a sua preferência por qualidade ponderada pela própria qualidade do carro.

Os dados utilizados para o modelo econométrico são os preços, as quantidades e as características dos carros. Estima-se o modelo separadamente para cada um dos três anos: 1954, 1955 e 1956; ainda, para cada ano, utiliza-se quatro diferentes comportamentos do mercado: competição Bertrand-Nash, conluio, hedônica e produto.

Bresnahan (1987) utiliza testes de modelos não-aninhados para verificar as hipóteses referentes ao mercado. Assim, o autor conclui que o comportamento do mercado em 1955 é consequência de uma quebra do conluio que estava presente nos anos adjacentes.

Com o intuito de flexibilizar mais o modelo de demanda desenvolvido por Bresnahan (1987), Berry et al. (1995) desenvolve um modelo randômico de utilidade para derivar a demanda. A utilizaçáo deste modelo reconhece que o consumidor tem preferência diferenciada que não é observável, assim, consumidores podem ter diferentes preferências sobre as características, por exemplo, dimensão do porta-malas ou do próprio carro é preferida para quem tem filhos, mas pode não ser para quem não os tem.

Modelos randômicos demandam um esforço de modelagem e computacional maior devido a maior complexidade. Os trabalhos de Berry (1994) e Berry et al. (1995) apresentam uma metodologia que usa dados agregados para estimar coeficientes logit randômicos de um modelo de demanda que caracteriza a diferença da preferência do consumidor. $\mathrm{Na}$ modelagem também são captadas as características não observadas do bem como: elementos 
subjetivos como a beleza do carro, erros de medição das características e qualquer outro efeito que façam a versão ser desejada pelos consumidores. A flexibilidade introduzida reduz o potencial do viés na estimação.

No trabalho de Berry et al. (1995) assume-se que o equilíbrio é tal como especificado pela teoria de Bertrand, utilizando uma função de demanda que elimine viés e obtendo os parâmetros de custo. Assim, desenvolve-se uma metodologia empírica analisando a demanda e a oferta de bens diferenciados e aplica-se para estudar o equilíbrio no mercado automotivo dos Estados Unidos entre 1971 e 1990. Utilizando dados anuais de preço, quantidade e características agregados por versão, estima-se a demanda e oferta com uma especificação funcional da demanda mais flexível que Bresnahan (1987) e, obtém parâmetros de custo e demanda para cada versão.

Rapson (2009) utiliza a modelagem da demanda mais flexível desenvolvida por Berry et al. (1995) para revisitar o estudo de Bresnahan (1987). Desta forma, aplica-se o modelo de coeficientes randômicos logit, que representam um comportamento mais realista para a demanda do que o modelo determinístico desenvolvido por Bresnahan, proporcionando elevada probabilidade dos maiores markups entre preço e custo serem atribuídos apropriadamente ao comportamento de uso de poder de mercado. As conclusões obtidas utilizando o mesmo teste de hipóteses de Bresnahan (1987) indicam que não se pode rejeitar a competição na forma de Bertrand em favor de conluio, o que contrapóe os resultados de Bresnahan, assim, apresentando um resultado surpreendente em que as firmas não estavam maximizando lucro no ano de 1955.

Sudhir (2001) também utiliza o modelo estrutural de Berry et al. (1995) para estudar o comportamento competitivo na precificação no mercado automotivo dos Estados Unidos entre os anos de 1981 e 1990. Para aferir a competitividade do setor é mensurado o desvio em relação a condição de Bertrand, tal como especificado em Bresnahan (1987), desta forma, permitindo uma segregaçáo entre os efeitos de demanda e custo dos efeitos de competição, visto que a abordagem de Bertrand considera os efeitos de demanda e custo. Desta forma, Sudhir (2001) conclui que se a firma perseguir um objetivo que pondera positivamente em relação ao lucro de seus competidores, o equilíbrio será mais cooperativo que Bertrand, visto que a cooperação perfeita é obtida se as ponderaçôes forem as mesmas para o lucro de todas as firmas.

Jin (2014) aplica também o modelo de Berry et al. (1995) para investigar a conduta de refinarias de combustíveis na Coreia do Sul. O autor examina qual dos modelos de conduta são aplicados naquele mercado: competição Bertrand-Nash ou conluio. $\mathrm{O}$ autor utiliza dados semanais do varejo de combustível no período de abril de 2009 a julho de 2010, combinando o modelo estrutural de Berry et al. (1995) com teste de Rivers e Vuong (2002). Jin (2014) conclui que o modelo de competição de Bertrand-Nash é o que melhor explica a conduta das refinarias no mercado de gasolina da Coreia do Sul.

Com relaçáo ao mercado automotivo brasileiro, pode-se citar o desenvolvimento de Negri (1998) que analisa de forma agregada os segmentos por meio das elasticidades de demanda, obtendo o resultado de que as receitas das firmas têm uma variaçáo proporcionalmente maior que os preços. Utilizando a teoria NEIO, Farias (2009) analisa a competitividade para o segmento de picapes pequenas por meio da demanda, tal como 
proposto por Cotterill et al. (1996), considerando a concorrência do tipo Bertrand e produtos diferenciados. O poder de mercado é identificado pela relação entre a elasticidade de plena cooperação com a elasticidade da demanda observável, definindo o índice de Cotterill.

Aplicado aos principais modelos do segmento de picapes pequenas: Fiat Strada, Volkswagen Saveiro, Chevrolet Montana e Ford Courier, entre outubro de 2003 e maio de 2007, Farias (2009) consegue inferir que a Fiat Strada possui maior poder unilateral e que a Volkswagen Saveiro é detentora de maior poder cooperativo. Desta forma, a Fiat Strada consegue manter o preço com markup proporcionalmente maior em relaçáo ao custo do que os demais modelos ao passo que a Volkswagen Saveiro usufrui da posição de líder sendo os outros modelos seguidores em estratégias de aumento de preço. Por fim, o poder de mercado observável maior é da Volkswagen Saveiro, que apesar de ter um poder unilateral inferior ao da Fiat Strada, a supera quando considerado o poder cooperativo. Desta forma, os resultados do estudo evidenciam existência de poder de mercado no oligopólio diferenciado no segmento de picapes pequenas.

O trabalho de Petterini e DeSouza (2009) é pioneiro em utilizar o modelo de Berry et al. (1995) para veículos novos no mercado brasileiro, aplicando para o período entre 2005 e 2008 e, permitindo estimar as elasticidades preço, preço cruzada e o markup de cada versão. As variáveis explicativas utilizadas são: uma dummy para veículos populares, uma para bicombustíveis, a relação entre potência e massa e uma trend para os anos. Petterini e DeSouza (2009) consideram principalmente carros populares e sedans médios, não utilizando picapes no estudo. Para o ano de 2008, a média do markup ponderada pelas vendas para as versóes populares foi de 11,9\%, o menor markup foi do Ford Ka de 7,6\% e o maior do Peugeot 206 de 15\%. Dando continuidade, DeSouza et al. (2010) utiliza o modelo de Berry et al. (1995) para simular o impacto sobre a firma e o consumidor de uma reduçáo de impostos no mercado automotivo brasileiro. Neste trabalho aplica-se um método mixed-logit, ao invés do logit utilizado em seu trabalho anterior, que permite maior flexibilidade para as elasticidades cruzadas. O período e as variáveis explicativas são as mesmas de Petterini e DeSouza (2009). Para o ano de 2008, comparando com Petterini e DeSouza (2009), a média do markup ponderada pela quantidade vendida para todo o mercado estimada é $5,1 \%$ maior. Por fim, a conclusão indica que $78,2 \%$ do ônus tributário é pago pelos consumidores.

Jacob (2015) destaca a importância do segmento de carros populares no Brasil e aponta que, em média no período de 2005 a 2010, cerca de $70 \%$ das vendas desse segmento foram de apenas quatro modelos: Gol, Pálio, Uno e Celta. Assim, evidencia também a concentração no mercado de carros populares. Destacada a importância desse segmento e a concentração de mercado em poucas firmas e modelos de carros, a autora propóe analisar o poder de mercado no segmento de carros populares brasileiro. Jacob (2015) aplica o modelo proposto por Cotterill, Franklin e Ma (1996) - CFM - em dados do período de 2005 a 2010 e detecta que as firmas que produzem estes quatro modelos de carros apresentam poder de mercado. Isto é, são capazes alavancar lucros econômicos estabelecendo preços acima do custo marginal. Constata-se ainda que há rivalidade na comercialização de Gol e Pálio e cooperação para Celta e Uno. 
Pires (2017) analisa o efeito de fusões e aquisições no mercado de picapes médias. O autor emprega o modelo Antitrust Logit Model (ALM), objetivando auxiliar os órgáos reguladores em análises antitruste e estimação de demanda. Pires (2017) conclui que os preços aumentam posteriormente a fusóes entre as cinco maiores firmas que atuam no segmento. $\mathrm{O}$ aumento de preços pós fusão foi ainda maior quando as transaçóes envolvem as duas maiores firmas do segmento.

O presente trabalho utiliza a teoria NEIO para o mercado de picapes pequenas, assim como Farias (2009), porém aplica uma metodologia que inclui atributos observáveis que caracterizam cada uma das versões de automóvel, considerando, portanto, as diferenças entre eles e sendo mais adequado para produtos diferenciados, tal como em Petterini e DeSouza (2009) e DeSouza et al. (2010).

\section{METODOLOGIA}

O modelo utilizado foi o desenvolvido por Berry et al. (1995), um modelo estrutural de demanda e oferta, onde aplica-se um modelo randômico de utilidade para derivar a demanda e assume-se que o logaritmo do custo marginal é linear em relaçáo ao custo dos atributos.

O método para estimar os parâmetros da demanda foi desenvolvido e detalhado por Berry (1994). Este método é uma abordagem que considera os valores não observados dos atributos do bem e se consolidou como uma ferramenta padrão para caracterizar a demanda de bens diferenciados (LEE, 2007). Esta modelagem também permite identificar parâmetros estruturais, sendo assim, útil para avaliar hipóteses múltiplas de comportamento. A escolha do consumidor é discreta, entre comprar ou não certa versão, assim, afetando a função de utilidade com um ganho, no caso da compra da versão, em função dos atributos ou por conta do consumo de um outro bem. A metodologia é baseada em Rapson (2009), assim, a utilidade indireta segue a seguinte forma ${ }^{4}$ :

$$
u_{i j}=\alpha p_{j}+X_{j} \beta+\xi_{j}+\sum_{k=1}^{K+1} \sigma_{k} x_{j k} v_{i k}+\varepsilon_{i j}
$$

Onde "i" é referente ao indivíduo e " $"$ " a versão da picape, "p" é o preço, " $\alpha$ " é a utilidade marginal do capital, " $X$ " é o vetor de atributos do veículo, " $\beta$ " é o vetor de parâmetros de preferência média da população aos atributos, " $\xi$ " são os atributos não observáveis, " $\sigma$ " é uma ponderação de um componente idiossincrático do atributo que reflete a média da população, sendo igual a todos os indivíduos, " $v$ " é uma ponderação idiossincrática de um atributo por um indivíduo e " $\varepsilon$ " é um choque randômico.

Os atributos observáveis estudados nas equaçóes da utilidade e custo foram escolhidos com base na disponibilidade da informação e são: potência do motor em "horse power"; motor em cilindrada; área projetada multiplicando o comprimento pela largura e sendo representado em metro quadrado; roda, que é mensurado em polegadas e representa o diâmetro da roda; volume da caçamba em litros; depreciação que é considerada como o delta percentual entre o preço de um carro novo e o preço de um carro usado com dois anos;

4 As descriçôes e notaçôes das equaçôes do modelo econométrico são baseadas em Rapson (2009). 
quantidade de lugares para ocupantes; tamanho da cabine que é a medida do comprimento da mesma e que diferencia de forma geral entre a cabine simples, a estendida e a dupla; carga em quilogramas representando a capacidade de carregamento; desempenho de zero a cem quilômetros por hora medido em segundos; economia de combustível em quilômetro por litro; cabine medida em metros e representando o comprimento; direção assistida como variável binária, apresentando valor zero na ausência de direção assistida e um para quando se tem o sistema e apenas para a equação de custo a quantidade vendida. A utilidade é decomposta entre média " $\delta$ " e idiossincrática " $\mu$ ":

$$
\begin{aligned}
& \delta_{j}=X_{j} \beta+\xi_{j} \\
& \mu_{i j}=\alpha p_{j}+\sum_{k=1}^{K+1} \sigma_{k} x_{j k} v_{i k}+\varepsilon_{i j}
\end{aligned}
$$

A modelagem considera aumento na sua utilidade em função dos atributos da versão, sendo que todos os consumidores estáo sujeitos aos mesmos atributos de cada versão. Um outro ponto são os atributos não observáveis em cada versão, por não serem mensuráveis como: estilo, prestígio da marca, reputação, experiência com outras versóes e propaganda; todavia, são considerados como percebidos pelos consumidores. Com a utilidade definida, escreve-se a probabilidade de um indivíduo escolher uma certa versão:

$$
\operatorname{prob}_{i j}=\frac{\exp \left(\delta_{j}+\mu_{i j}\right)}{\sum_{h=1}^{J} \exp \left(\delta_{h}+\mu_{i h}\right)}
$$

Sendo a participação de mercado de uma dada versão a soma referente a todos os indivíduos:

$$
\hat{s}_{j}=\frac{1}{I} \sum_{i=1}^{I} \operatorname{prob}_{i j}
$$

Como os atributos não observáveis " $\xi$ ", também interpretados como erro, são correlacionados com a variável preço, tem-se um problema de endogeneidade, fazendose necessário o uso de técnicas de estimação com variáveis instrumentais. As variáveis instrumentais serão tais como detalhadas em Bresnahan et al. (1997). Desta forma, os parâmetros não lineares serão estimados numericamente por meio do algoritmo de busca ótimo descrito em Lagarias et al. (1998). Atributos observáveis exógenos podem ser considerados como instrumentos. Ainda, nas condições em que as derivadas cruzadas não são zero, os atributos das versóes em questáo também podem ser utilizados como instrumentos.

$$
\begin{aligned}
& Z_{1}=X_{j} \\
& Z_{2}=\sum_{k \neq j \in F_{f}} X_{k} \\
& Z_{3}=\sum_{k \notin F_{f}} X_{k}
\end{aligned}
$$

Uma estimativa da utilidade média de uma dada versão " $\delta$ " pode ser determinada como a soluçáo de um algoritmo de ponto fixo que equaciona as parcelas de mercado observadas e as estimadas:

$$
\delta^{h+1}=\delta^{h}+\operatorname{lns}^{\text {observado }}-\ln \hat{s}
$$


Do lado da oferta, define-se que cada firma tem um conjunto " $F$ " de versões. Assumese que o logaritmo do custo marginal é linear em relação ao custo dos atributos. Da mesma forma que definido para a demanda, os atributos são divididos entre os que são observáveis " $X$ ” e os que não o são " $\omega$ ". Logo, dadas as suposiçôes, define-se o custo marginal de uma versão como:

$$
\ln \left(m c_{j}\right)=X_{j} \gamma+\omega_{j}
$$

Sendo " $\gamma$ " um vetor de parâmetros a ser estimado. Sendo " $M$ " o tamanho do mercado, " $s$ " a parcela da versão e " $f$ o índice referente a uma dada firma, pode-se considerar o lucro variável da firma:

$$
\pi_{f}=\sum_{j \in F_{f}}\left(p_{j}-m c_{j}\right) M s_{j}
$$

Cada firma determina os preços de suas versōes para maximizar o lucro. As condições de primeira ordem para uma versão " "j" são:

$$
0=s_{j}+\left(p_{j}-m c_{j}\right) \frac{\partial s_{j}}{\partial p_{j}}
$$

Considerando que a firma produza duas versóes: “ $j$ " e " $j+l$ ', os preços das suas versōes serão definidos para maximizar o lucro, resultando na seguinte condição de primeira ordem:

$$
0=s_{j}+\left(p_{j}-m c_{j}\right) \frac{\partial s_{j}}{\partial p_{j}}+\left(p_{j+1}-m c_{j+1}\right) \frac{\partial s_{j+1}}{\partial p_{j}}
$$

Generalizando:

$$
0=s_{j}+\sum_{r \in F_{f}}\left(p_{r}-m c_{r}\right) \frac{\partial s_{r}}{\partial p_{j}}
$$

Sendo " $r$ " referente as versões da firma. As derivadas cruzadas em relação ao preço são interpretadas tanto do ponto de vista dentro da firma como entre as firmas, desta forma compondo as alternativas de comportamento: competição entre todos as versôes, cooperação entre todas as versóes e cooperação entre as versóes da mesma firma. Para modelar estas alternativas utiliza-se a mesma estratégia aplicada por Bresnahan (1987) e Rapson (2009), definindo uma matriz " $\Delta$ " de derivadas cruzadas tal como:

$$
\Delta_{j r}=\left\{\begin{array}{l}
\frac{-\partial s_{r}}{\partial p_{j}} \text { caso exista cooperação } \\
0 \text { caso não exista cooperação }
\end{array}\right.
$$

Assim, atribuindo valores aos parâmetros não-lineares e com a estimaçáo dos atributos não observáveis pelo lado da demanda, é possível estimar o markup do preço sobre o custo marginal; na forma matricial, Rapson (2009), tem-se:

$$
0=s(p, x, \xi ; \theta)+\Delta(p, x, \xi ; \theta)[p-c m]
$$

Onde " $\theta$ " são parâmetros não lineares e " $x$ " são os atributos observáveis. Rearranjando a equaçáo 16 e combinando com a equação 10 chega-se na expressão de custo com a variável não observável: 


$$
\ln \left(p-\frac{s(p, x, \xi ; \theta)}{\Delta(p, x, \xi ; \theta)}\right)=\varphi \gamma+\omega
$$

Sendo " $\varphi$ " o vetor de atributos, pode-se estimar “ $\omega$ ” por meio de cálculo dos resíduos ajustados condicionado a estimação de " $\gamma$ ".

O algoritmo de simulação baseado em Berry (1994) é disponibilizado por Wildenbeest (2016) e é aplicado com o software Matlab. Assim, tem-se como ponto de partida uma escolha aleatória para preferência individual " $v$ " - definida na Equação 3, que é uma ponderação idiossincrática de um atributo por um indivíduo. Desta forma, calcula-se a utilidade idiossincrática e com um algoritmo de ponto fixo tal como na Equação 9 convergese para encontrar a utilidade média. Estima-se com a equação 2 por regressáo linear os atributos não observáveis. Calculam-se as derivadas cruzadas da parcela de mercado prevista pelo preço da versão, seguindo a estratégia de cooperaçáo ou competiçáo de acordo com a alternativa em questão, seguindo a Equação 15. Da Equação 17 obtêm-se por regressão linear os parâmetros da função custo, concluindo a estimativa dos parâmetros do modelo estrutural.

Agora resta otimizar a preferência individual aplicando o Método dos Momentos Generalizados (HARRIS; MATYAS, 1999), utilizando como função objetivo a amostra análoga da condição de ortogonalidade nas variáveis instrumentais e das não observáveis.

$$
\mathrm{E}[\mathrm{Z} \xi(\theta)]=\mathrm{E}[\mathrm{Z} \omega(\theta)]=0
$$

As variáveis instrumentais serão tais como detalhadas em Bresnahan et al. (1997). Desta forma, os parâmetros não lineares " $\theta$ " seráo estimados numericamente por meio de um algoritmo de busca ótimo.

O objetivo do teste é verificar a existência de poder cooperativo, que consiste em as firmas agirem coordenadamente para aumentar o lucro individual, no caso deste estudo, assumindo a estratégia de aumento do preço. As alternativas de comportamento das firmas para caracterizar o nível de competitividade do mercado são não aninhadas, desta forma, pretende-se utilizar o método descrito em Rivers e Vuong (2002), que é adequado para tratar de modelos não especificados completamente. A estatística é uma função da diferença entre os valores da função objetivo minimizada pelo método dos momentos generalizados no valor ótimo e uma estimativa da variância entre os objetivos:

$$
T=\frac{\sqrt{J}}{\widehat{\sigma}}\left(Q_{1}\left(\theta_{1}\right)-Q_{2}\left(\theta_{2}\right)\right)
$$

Onde " $Q$ " é o resultado da funçâo objetivo com os parâmetros ótimos, " $\theta$ " são os parâmetros ótimos e " $\sigma$ " é a estimativa da variância entre os objetivos; sendo os índices um e dois referentes aos modelos a serem comparados.

A aplicação do teste foi construída de forma que a hipótese nula é tal que os modelos de competição e cooperação são indistinguíveis. A hipótese nula é testada contra duas alternativas que estabelecem que um dos modelos tem ajuste superior aos dados em relação ao outro modelo, formando um teste bicaudal da seguinte forma: 


$$
\begin{aligned}
& H_{0}: \lim _{J \rightarrow \infty} \sqrt{J}\left(Q_{1}\left(\theta_{1}\right)-Q_{2}\left(\theta_{2}\right)\right)=0 \\
& H_{1}: \lim _{J \rightarrow \infty} \sqrt{J}\left(Q_{1}\left(\theta_{1}\right)-Q_{2}\left(\theta_{2}\right)\right)=-\infty \\
& H_{2}: \lim _{J \rightarrow \infty} \sqrt{J}\left(Q_{1}\left(\theta_{1}\right)-Q_{2}\left(\theta_{2}\right)\right)=+\infty
\end{aligned}
$$

A estatística é comparada com os valores críticos de uma distribuiçấo normal e vai indicar qual dentre os modelos é melhor ajustado aos dados.

Os dados a serem utilizados são: preço, quantidade e atributos das versões. Os dados de preço e quantidade são mensais e se referem apenas a veículos novos vendidos no período de janeiro de 2001 a maio de 2014. Os dados de quantidade têm como fonte a Associação Nacional dos Fabricantes de Veículos Automotores (ANFAVEA) e a Federação Nacional da Distribuição de Veículos Automotores (FENABRAVE). Já os dados de preços são originários de pesquisas da Fundação Instituto de Pesquisas Econômicas (FIPE). Importante comentar que o mercado de picapes pequenas é afetado por isenção de impostos para pequenos produtores rurais, desconto este que não está refletido nos preços da FIPE. Os preços dos veículos foram deflacionados com o INPC (Índice Nacional de Preços ao Consumidor) com referência em janeiro de 2001. Por fim, os dados dos atributos de cada versão de picapes pequenas foram compilados dos sites das montadoras.

\section{RESULTADOS E DISCUSSÃO}

Inicia-se a análise com os dados de preço de cada firma ponderado pela quantidade vendida que se denomina como preço médio. Este preço médio refere-se ao realizado pelas firmas e está na Figura 1. Observa-se oscilaçôes de preços momentâneas durante os períodos de crise como em 2003 e 2009; também pode-se perceber redução progressiva iniciando-se em torno de 2007. Por outro lado, eventos de lançamentos de novas versóes são acompanhados de aumento de preços, como por exemplo os lançamentos da Fiat em 2001, 2004, 2009 e 2012 e da GM em 2004 e 2010. 
Figura 1 - Preço real médio de picapes pequenas comercializadas no Brasil, 2001-2014

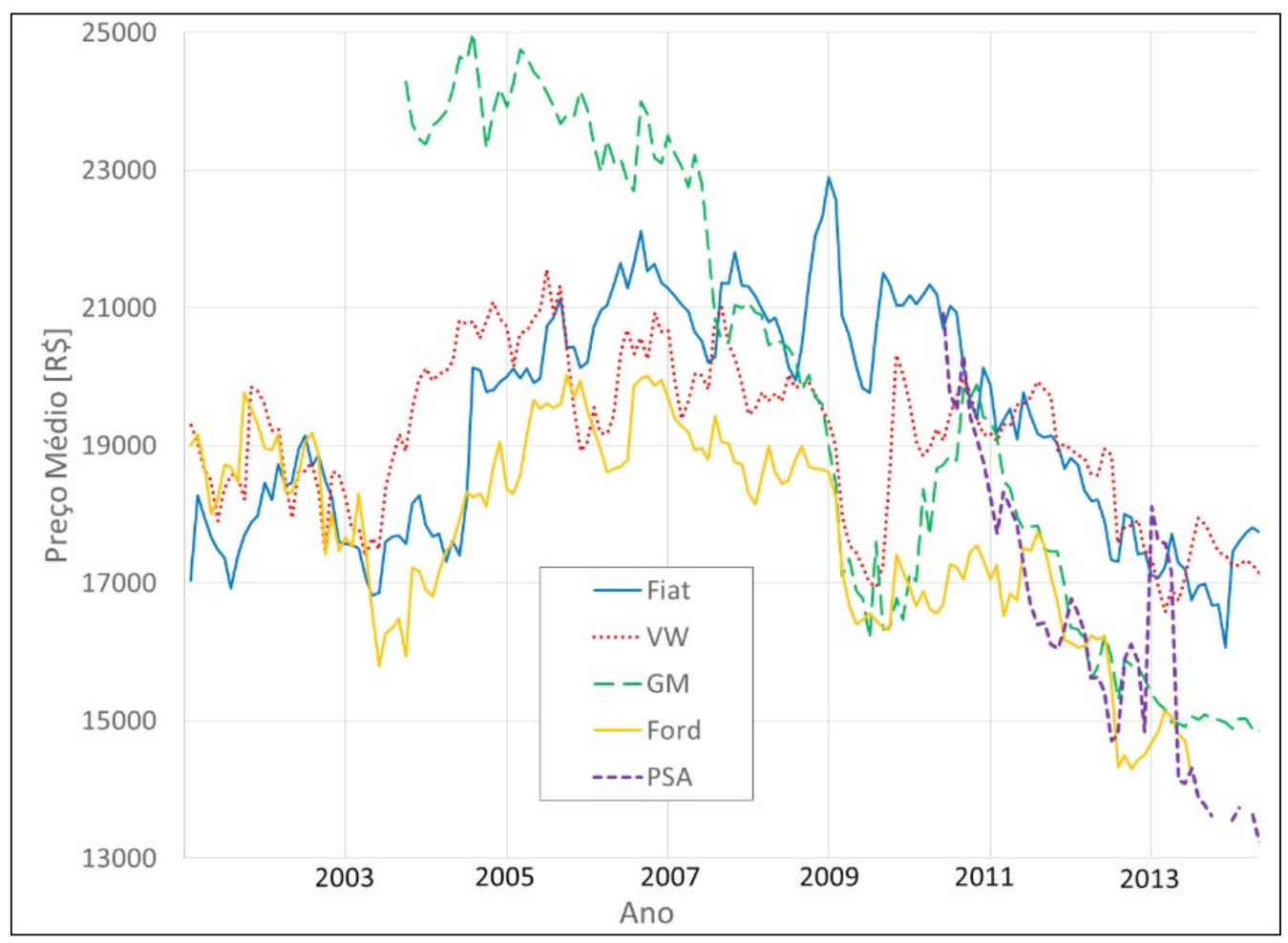

Fonte: Elaborado pelos autores com base nos preços FIPE (a preços de janeiro de 2001).

A Tabela 1 apresenta os parâmetros estimados e os respectivos erros padróes. Iniciando a análise pelo lado da demanda, observa-se que o coeficiente estimado para o preço, que indica a sensibilidade preço do consumidor, está de acordo com a teoria econômica uma vez que apresenta sinal negativo. Destaca-se que o valor da elasticidade preço média, encontrada nessa pesquisa, é próximo a valores encontrados na literatura para o setor de automóveis. Jacob (2015) estimou a elasticidade preço direta da demanda de -1,22, -1,35, -1,87 e -2,15, respectivamente, para Pálio, Gol, Uno e Celta - a autora usou dados do período de 2005 a 2010. 
Tabela 1 - Estimativas do modelo estrutural para picapes pequenas no Brasil

\begin{tabular}{|c|c|c|c|c|c|c|c|}
\hline \multirow{2}{*}{$\frac{\text { Demanda }}{\text { (Preferência do Consumidor) }}$} & \multicolumn{2}{|c|}{$2001-2014$} & & \multirow{2}{*}{$\frac{\text { Oferta }}{\text { (Custo) }}$} & \multicolumn{3}{|c|}{$2001-2014$} \\
\hline & $\begin{array}{l}\text { Parâmetro } \\
\text { Estimado }\end{array}$ & $\begin{array}{l}\text { Desvio } \\
\text { Padrão }\end{array}$ & & & $\begin{array}{l}\text { Parâmetro } \\
\text { Estimado }\end{array}$ & $\begin{array}{l}\text { Desvio } \\
\text { Padrão }\end{array}$ & \\
\hline Preço & -1.204 & 0.012 & $*$ & & & & \\
\hline Constante & 16.928 & 1.289 & $*$ & Constante & -3.573 & 1.089 & $*$ \\
\hline Depreciação & -2.464 & 0.481 & $*$ & Quantidade de lugares & 0.094 & 0.079 & \\
\hline Quantidade de lugares & -0.040 & 0.078 & & Capacidade de carga & 0.794 & 0.126 & $*$ \\
\hline Cabine & -0.315 & 0.062 & $*$ & Cabine & 0.071 & 0.068 & \\
\hline Potência do motor & -4.434 & 0.181 & $*$ & Volume caçamba & -0.831 & 0.286 & $*$ \\
\hline Desempenho 0-100 kph & -0.489 & 0.043 & $*$ & Potência do motor & 0.006 & 0.118 & \\
\hline Economia combustível & 0.016 & 0.003 & $*$ & Economia combustível & -0.395 & 0.251 & \\
\hline Roda & -0.913 & 0.057 & $*$ & Roda & 0.130 & 0.060 & $* *$ \\
\hline Direção assistida & 0.411 & 0.089 & $*$ & Quantidade & -0.138 & 0.031 & $*$ \\
\hline
\end{tabular}

Nota: $\left({ }^{*}\right)$ significativo a $1 \%$; $\left({ }^{* *}\right)$ significativo a $5 \%$.

Fonte: Elaborado pelos autores.

De forma geral, os parâmetros estimados para a equação da demanda indicam a preferência média de escolha dos consumidores que afeta a utilidade, ao passo que o desvio padrão mensura a heterogeneidade na preferência para cada atributo. Como as picapes pequenas são veículos destinados a transporte de pequenas cargas, apresentam caráter funcional, onde se espera maior utilidade para atributos como economia de combustível, cabine simples e baixo esforço de direção.

A depreciação que mensura quanto se perde percentualmente no valor do carro após dois anos de uso é percebida pelo consumidor e a preferência é por veículos cujo valor tem menor alteração com o passar dos dois anos.

Maior quantidade de lugares e cabines maiores como dupla ou estendida não são preferidos pelo consumidor por apresentarem menos funcionalidade para o transporte de carga, uma vez que o espaço destinado a caçamba é comprometido com o destinado a passageiros. Quanto à potência do motor, nota-se que a preferência do consumidor é por versóes menos potentes, o que era de se esperar, uma vez que as versóes com motores de menores cilindradas possuem maior aceitação no mercado por resultarem em maior economia de combustível. Tal resultado também foi encontrado por DeSouza et al. (2010). De forma similar encontram-se os resultados para o parâmetro de desempenho de zero a cem quilômetros por hora, visto que existe um compromisso entre desempenho em aceleração e economia de combustível. Uma melhor economia de combustível é indicada como preferido pelo consumidor, o que está em linha com a expectativa, em especial no Brasil e neste segmento onde o veículo é funcional.

Com relação ao tamanho da roda, a preferência esperada por rodas menores se confirma, novamente indicando maior utilidade na funcionalidade do veículo e menos na estética. Já a direção assistida hidraulicamente para reduzir os esforços em manobras de estacionamento apresenta maior preferência, o que é condizente com a expectativa. 
Do lado da oferta, as estimativas dos parâmetros da equação de custo também estão alinhadas com a expectativa. De forma geral, o custo é maior para versóes com mais lugares e maiores cabines, rodas e motores. A quantidade de lugares e o tamanho da cabine refletem em custo maior, o que é coerente uma vez que maior estrutura metálica com mais peças são requeridas e também na parte interna como banco e acabamento. Em contrapartida, com uma maior cabine, menor é o volume da caçamba, por isto encontra-se o parâmetro indicando um menor custo para maior volume de caçamba. Também se observa que as variáveis quantidade de lugares e cabine são estatisticamente não significativas e a variável volume de caçamba é estatisticamente significativa, alinhando o resultado com a expectativa de correlação entre as três variáveis, conforme apresentado na descrição do modelo econométrico. A capacidade de carga reflete uma carroceria mais reforçada e também remete a motores mais potentes, também indicando maior custo.

A potência do motor também remete um maior custo, seja por maior cilindrada ou por carregar tecnologias que permitam melhor desempenho. Carros com melhor economia de combustível possuem custo menor por terem motor menor e apresentar menos conteúdo, assim, com massa menor. A roda maior também apresenta custo maior, além de ter mais material, normalmente rodas maiores são de material mais nobre como liga de alumínio. Quanto à quantidade, o parâmetro estimado reflete a teoria econômica do efeito escala, onde quanto maior a escala de produçáo, menor o custo médio do veículo.

A Figura 2 ilustra o markup estimado de cada versão ao longo dos anos. Observa-se picos de markup alinhados com eventos de lançamento.

Figura 2 - Markup médio estimado por versão de picapes pequenas no Brasil

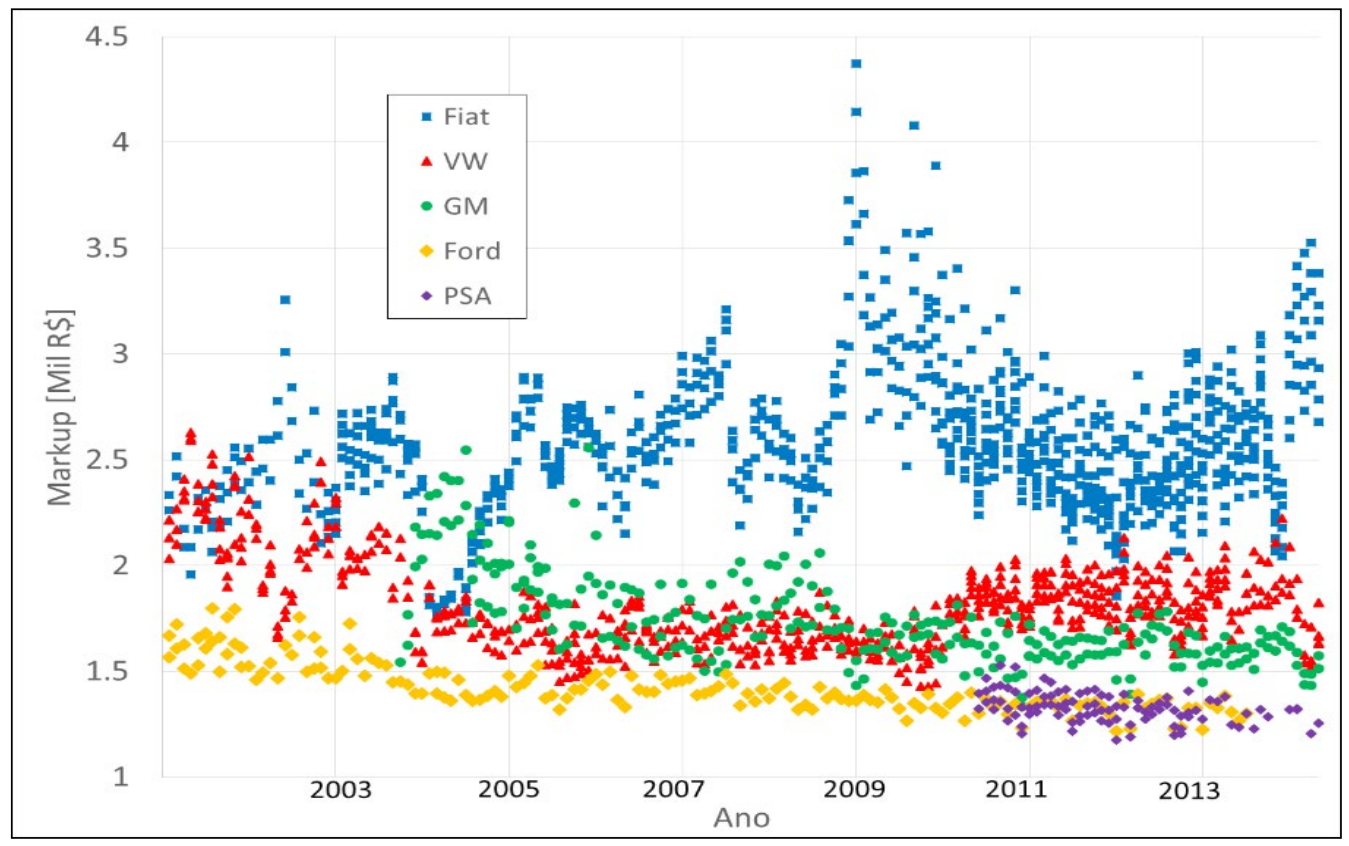

Fonte: Elaborado pelos autores. 
A Fiat de forma geral consegue negociar suas versóes com maior markup, já a VW e a GM alternam a segunda posição. A Ford e a PSA não conseguem atingir o mesmo nível de markup que as demais, sempre trabalhando com valores inferiores. Interessante observar que durante o período de crise em 2009, que também culminou com o lançamento de uma nova geração da Fiat Strada, a montadora atingiu seu maior pico de markup o que pode ser explicado pelo lançamento e pela estratégia para gerenciar a crise. Mesmo tendo uma redução nas vendas notável em todas as montadoras em 2009, observa-se que enquanto a Fiat aumentava o preço de suas versóes, todas as demais estavam reduzindo continuamente. Ainda assim, a Fiat ainda mantinha vendas maiores que as demais.

A Figura 3 apresenta o markup percentual sobre o preço de cada versão. Observase novamente a superioridade da estratégia da Fiat que permite trabalhar com margens maiores. Até 2004 a Ford está claramente praticando margens menores, depois alinhandose com VW e GM e, em 2009, em sequência conseguindo níveis inferiores de markup. A PSA por todo o período que participa do segmento consegue praticar margens entre as mais baixas. $\mathrm{O}$ markup percentual em relação ao preço, de certa forma, se mostra mais similar entre as firmas, exceto pela Fiat que possui valores muito superiores. Os resultados sugerem que a Fiat possui maior poder unilateral, seguida da Volkswagen e GM, indicando que existem poucos produtos substitutos e que a diferenciação de produtos é percebida e apresenta preferência pelo consumidor, como fidelização às firmas. A média do markup de todos os modelos de picapes pequenas ponderada pela quantidade vendida é de 11,6\%, comparável com o valor encontrado para as versões populares em 11,9\% no trabalho de Petterini e DeSouza (2009). Verifica-se ainda, proximidade com o estudo do Sindipeças (BRASIL, 2012), indicando em torno de $10 \%$ de markup sobre o preço ao consumidor no mercado automobilístico brasileiro. 
Figura 3 - Markup percentual estimado para o segmento de picapes pequenas no Brasil de cada firma, 2001-2014

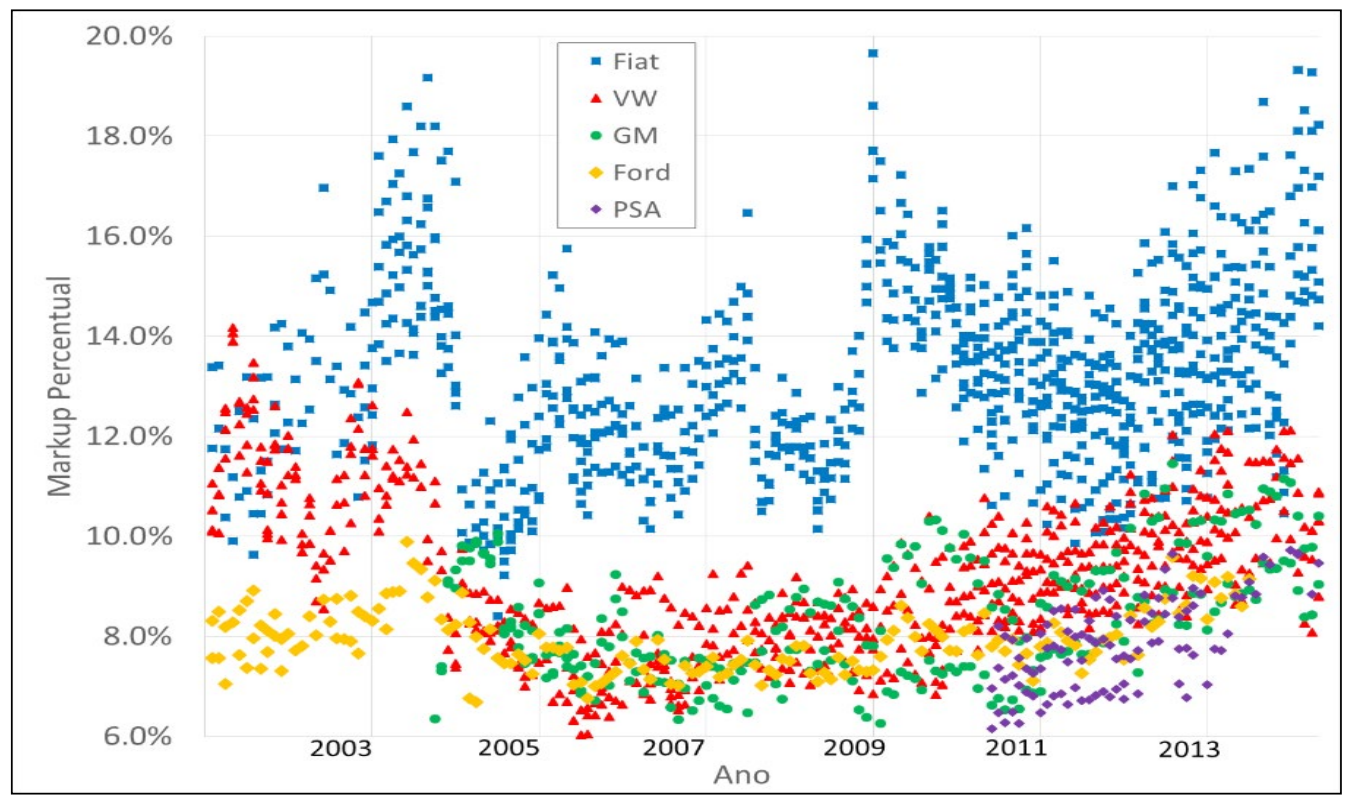

Fonte: Elaborado pelos autores.

As alternativas de comportamento das firmas para caracterizar o nível de competitividade do mercado são testadas com o método de Rivers e Vuong (2002). Cinco diferentes alternativas de competição e cooperação são avaliadas: condição onde as firmas competem entre todas seguindo o modelo de Bertrand para oligopólio, cooperação entre Fiat e VW, cooperação entre Fiat e GM, cooperação entre VW e GM, cooperação entre Fiat, VW e GM e, cooperação entre todas as firmas. A competição Bertrand considera que as firmas competem tal como num oligopólio de Bertrand, tendo como variável estratégica o preço do produto e, considera-se que as funçóes de reação de preço de cada firma se encontram no ponto de equilíbrio de Nash (CHURCH e WARE, 2000). Na condição de cooperação as firmas definem o preço de forma a otimizar o lucro como se todos as versões fossem de um mesmo grupo de montadoras. Os acordos de cooperação não são identificados como tácito ou explícito, o modelo apenas considera que as estratégias de precificação das firmas podem ser coordenadas.

A hipótese nula, na qual os modelos de competição e cooperação são indistinguíveis, é testada contra duas alternativas que estabelecem que um dos modelos tem ajuste superior aos dados em relação ao outro modelo. A estatística apresentada na equação 19 pode ser comparada com o valor crítico de uma distribuição normal com média igual a zero e desvio padrão igual a um. Assim, segundo Rivers e Vuong (2002), quando o valor da estatística for negativo, indica que o modelo de Bertrand apresenta melhor ajuste aos dados do que o modelo descrito na respectiva coluna, favorecendo a hipótese $H_{1}$ da equação 21. Ainda, se o valor for estatisticamente significativo, pode-se rejeitar o modelo descrito na coluna a 
favor de Bertrand; ao passo que se o valor da estatística for positivo, favorecendo a hipótese $\mathrm{H}_{2}$ da equação 22, o modelo de cooperação apresenta melhor ajuste aos dados (RIVERS e VUONG, 2002). Para os testes, duas abordagens em relaçáo a partição do tempo foram empregadas. A primeira compreende todos os anos estudados, ou seja, de janeiro de 2001 a maio de 2014, ao passo que a segunda considera cada um dos últimos cinco anos com dados completos: 2009, 2010, 2011, 2012 e 2013. A Tabela 2 apresenta os resultados de todos os testes realizados.

Tabela 2 - Testes entre modelos de cooperação e competição

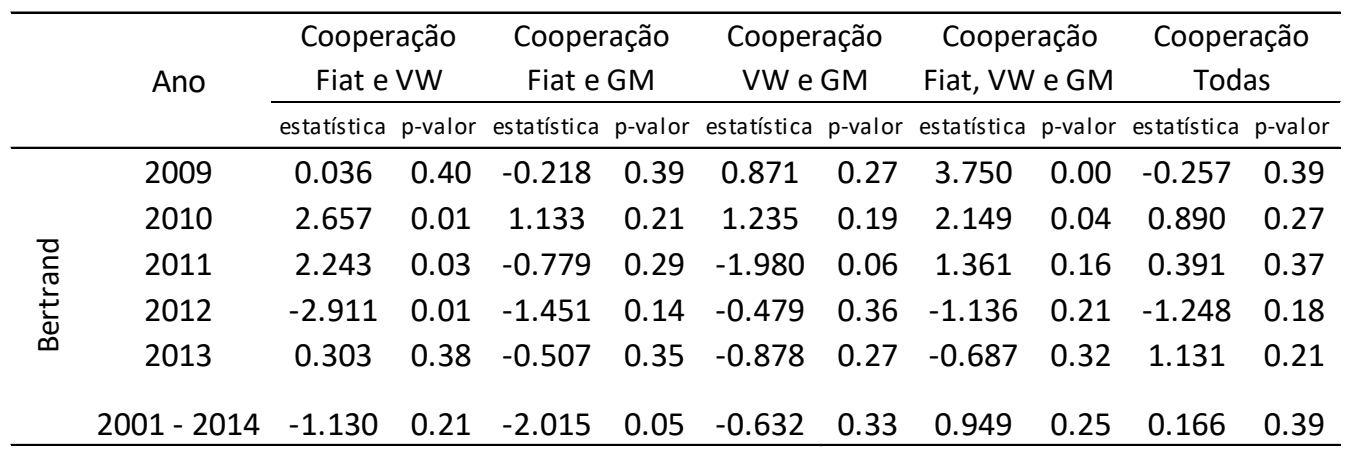

Fonte: Elaborado pelos autores.

Para o ano de 2009, é possível rejeitar com significância estatística o modelo de competição de Bertrand entre todas as firmas a favor da cooperaçáo das três maiores firmas em vendas: Fiat, VW e GM. O ano de 2009 foi marcado pela crise econômica e pela queda de vendas, conforme já explanado anteriormente. Neste mesmo ano o mercado automotivo foi alvo de redução de IPI e com exceção ao momento do lançamento da nova versão da Fiat Strada, estas três firmas praticaram reduções significativas nos preços de seus veículos.

No ano de 2010 todos os testes apresentam sinais positivos, ou seja, indicam que modelos de cooperaçáo possivelmente apresentam melhor ajuste aos dados. Foi possível rejeitar com significância estatística o modelo de competiçáo entre todas as firmas a favor dos modelos de cooperação entre Fiat e VW e entre Fiat, VW e GM. Este ano teve aumento gradual do IPI, e foi possível o aumento de preço concomitante entre Fiat e VW, seguidos pela GM.

Em 2011 dois testes apresentaram significância estatística: rejeição de competição entre todas as firmas a favor de cooperação entre Fiat e VW e, rejeição de cooperação entre VW e GM a favor de competiçáo entre todas as firmas. Neste ano a GM praticou aumentos significativos no preço de sua recém lançada nova versão da Montana, o que pode ter sido motivo de maior rivalidade com VW e uma possível cooperação desta última com a líder de mercado Fiat.

Em 2012 todos os testes apresentam sinais negativos sugerindo uma mudança estratégica das firmas e melhor ajuste aos dados do modelo de competição entre todas as firmas em relação qualquer modelo de cooperação. Contudo, com significância estatística verificou-se apenas a rejeição da cooperação entre Fiat e VW. Neste ano a Fiat lançou novas 
versões da Strada, o que pode ter aumentado a rivalidade com a VW, além disto, este ano teve momentos de estagnaçáo e queda de vendas quando comparado com o ano anterior, reflexo de uma economia com baixo crescimento (ANFAVEA, 2014).

Em 2013 não foi possível distinguir entre cooperação e competição em nenhum dos testes realizados. Observa-se que em 2011 e em 2012, provavelmente por decorrência dos lançamentos da GM e da Fiat, respectivamente, o teste identificou, com significância estatística, melhor ajuste do modelo de competição entre todas as firmas do que a cooperação da GM ou Fiat com a VW. Isto pode ser consequência da diferenciaçáo temporária causada pelo lançamento de novos produtos, o que permite vantagem competitiva e maior poder unilateral para a firma que efetua o lançamento, consequentemente, permitindo prática de preços e markups mais elevados.

Para a abordagem que considera todos os períodos estudados, a única alternativa que pode ser descartada com significância estatística a favor de Bertrand é a cooperação entre Fiat e GM. Este resultado indica que a cooperação entre Fiat e GM não é mais adequada que a competição entre todas as firmas. Desta forma os resultados corroboram com as conclusóes de Farias (2009), que sugerem a existência da presença de cooperação e de rivalidade entre as firmas, dependendo do período e das firmas em questão.

\section{CONCLUSÓES}

O modelo estimado apresenta resultados coerentes com a teoria econômica e caracteriza a preferência média de escolha dos consumidores. Os atributos preferidos pelo consumidor estão em linha com a lógica do segmento de picapes pequenas, que são veículos destinados a transporte de pequenas cargas. Como estes veículos apresentam caráter funcional, a preferência observada no modelo estimado foi para atributos como economia de combustível, cabine simples e maior capacidade de carga.

Analisando o markup, a Fiat de forma geral conseguiu negociar suas versóes com maior markup, já a VW e a GM alternaram a segunda posição. A Ford e a PSA não conseguiram atingir o mesmo nível de markup que as demais, sempre trabalhando com valores inferiores. Interessante refletir sobre a importância da escala de produção e o impacto no markup, visto que as empresas com maiores volumes de produçáo conseguiram reduzir o custo e aumentar o markup, assim, potencialmente atuando como pressáo à saída do segmento das empresas com volumes pequenos de produção. Portanto, firmas que desejem competir neste segmento devem esperar um consumidor fiel a Fiat e, entender a estratégia desta para conseguir tal condição. Assumindo concorrência oligopolista como Bertrand, os resultados do markup indicam que a Fiat possui maior poder unilateral, seguida da Volkswagen e GM, sugerindo que existem poucos produtos substitutos e que a diferenciaçáo de produtos é percebida e apresenta preferência pelo consumidor, como fidelização às firmas com maior poder mercado. Este poder unilateral é decorrente da existência de barreiras à entrada e da diferenciação do produto. Segundo Farias (2009), a Fiat assume estas condiçôes por lograr maior quantidade de inovaçôes e reestilizaçôes.

Outra conclusão importante é a coerência dos resultados de markup percentual com o estudo Petterini e DeSouza (2009) quando considerados os veículos populares. Ainda, 
verifica-se proximidade com o estudo do Sindipeças para o mercado automobilístico brasileiro (BRASIL, 2012).

Com o teste aplicado para comparar as alternativas de competição e cooperação e verificar se existe exercício de poder de mercado no segmento de picapes pequenas no mercado brasileiro foi possível demonstrar com significância estatística a existência de cooperação entre algumas firmas em alguns períodos. Para os anos de 2009 e 2010 foi possível rejeitar o modelo de competição de Bertrand entre todas as firmas em favor da cooperação das três maiores firmas em vendas: Fiat, VW e GM. Em 2011, dois testes apresentaram significância estatística: rejeição de competição entre todas as firmas a favor de cooperação entre Fiat e VW e, rejeição de cooperação entre VW e GM a favor de competiçẫo entre todas as firmas. Já em 2012 pode-se rejeitar a cooperação entre Fiat e VW a favor da competição entre todas as firmas. Em 2013 não foi possível distinguir entre cooperação e competição em nenhum dos testes realizados. Nos anos 2011 e 2012, os lançamentos da GM e da Fiat alteraram o comportamento estratégico das firmas levando à rejeição da cooperação em favor de competição. Foi possível identificar ainda que as diferenciaçôes temporárias causadas pelo lançamento de novos produtos mudam a dinâmica competitiva do mercado e permitem vantagem competitiva e maior poder unilateral para as firmas que efetuam o lançamento. Ressalta-se que a cooperação não é identificada no presente estudo como tácita ou explícita. Assim, no caso de cooperação, é possível apenas concluir que as firmas podem adotar estratégias de preços coordenadas.

Os resultados obtidos mostram a existência da presença de cooperação e de rivalidade entre as firmas, tal como observado por Farias (2009), condições estas provavelmente causadas pelas dinâmicas do mercado automotivo, com lançamentos de produtos novos, situaçóes distintas da economia nacional e intervençóes do governo.

Apesar do grande esforço em montar uma base de dados com nível de detalhamento diferenciado em relação aos trabalhos encontrados na literatura a pesquisa ainda apresenta algumas limitaçóes: a) os preços dos modelos de picapes consideradas na análise não consideram nenhum tipo de desconto concedido em vendas diretas (especialmente, empresas e produtores rurais); b) Utilizou-se o preço médio nacional, não considerando variaçôes regionais; c) não foi possível inserir no modelo empírico variáveis que representassem de forma direta atributos como estilo, marca, reputação, experiência com outras versões, propaganda, experiência com teste drive; d) Restrita disponibilidade de dados atualizada, por versão e motorização. Em pesquisas futuras sugere-se atualizar os dados para período mais recente, aplicar a modelagem em segmentos de carros populares, SUV e de picapes médias (nova tendência do mercado nacional). Ademais, sugere-se incorporar avaliaçóes de versóes do produto como proxy de qualidade percebida pelo consumidor.

\section{REFERÊNCIAS}

ABREU, D. External equilibria of oligopolistic supergames. Journal of Economic Theory. Vol. 39, p. 191-225, 1986. 
ANFAVEA. Anuário da indústria automobilística brasileira. Anuários de 2001 a 2014, ANFAVEA. Disponível em: < http://www.anfavea.com.br >. Acesso em: 11 de abr. 2015.

APPELBAUM, E. Testing price-taking behavior. Journal of Econometrics. Vol. 9, p. 283-299, 1979.

BERRY, S. Estimating discrete-choice models of product differentiation. Rand Journal of Economics. Vol. 25, p. 242-262, 1994.

BERRY, S., LEVINSOHN, J., PAKES, A. Automobile prices in market equilibrium. Econometrica. Vol. 63, p. 841-890, 1995.

BOONE, J. How (not) to measure competition. TILEC Discussion Paper 2007-014. 2007.

BRASIL. Secretaria de Acompanhamento Econômico do Ministério da Fazenda. Guia para análise econômica de atos de concentração econômica. SEAE, 2001. Disponível em: <http://www.seae.fazenda.gov.br/central_documentos/guias>. Acesso em: 20 jan. 2015.

BRASIL. Comissáo de Assuntos Econômicos. 2012. Disponível em: <http://www. senado.gov.br>. Acesso em: 20 de jan. 2015.

BRASIL. Conselho Administrativo de Defesa Econômica. Guia para análise de atos de concentração horizontal. Brasília, 2016. Disponível em: <http://www.cade.gov.br/acessoa-informacao/publicacoes-institucionais/guias_do_Cade/guia-para-analise-de-atos-deconcentracao-horizontal.pdf> Acesso em 12 jun. 2018.

BRESNAHAN, T. Departures from marginal cost pricing in the American automobile industry. Journal of Econometrics. Vol. 11, p. 201-227, 1981.

BRESNAHAN, T. The oligopoly solution concept is identified. Economic Letters. Vol. 19, p. 87-92, 1982.

BRESNAHAN, T. Competition and collusion in the American automobile industry: the 1955 price war. Journal of Industrial Economics. Vol. 35, p. 457-482, 1987.

BRESNAHAN, T. Empirical studies of industries with market power. Handbook of Industrial Organization. Amsterdam. North-Holland. 1989.

BRESNAHAN, T., STERN, S., TRAJTENBERG, M. Market segmentation and the sources of rents from innovation: personal computers in the late 1980s. Rand Journal of Economics. Vol. 28, p. 17-44, 1997.

CASOTTI, B. P., GOLDENSTEIN, M. Panorama do setor automotivo: as mudanças estruturais da indústria e as perspectivas para o Brasil. BNDES. 2008. 
CHURCH, J., WARE, R. Industrial organization: a strategic approach. Irwin McGrawHill. 2000.

COTTERILL, R., FRANKLIN, A., MA, L. Measuring market power effects in differentiated product industries: an application to the soft drink industry. University of Connecticut. 1996. Disponível em: <http://www.fmpc.uconn.edu/publications/rr/rr32. pdf>. Acesso em: 01 jun. 2018.

COX, D. R. Tests of Separate Families of Hypotheses. Proceedings of the Fourth Berkley Symposium on Mathematical Statistics and Probability. University of California Press, Berkeley, Vol. 1, pp. 105-123, 1961.

DESOUZA, S. A.; PETTERINI, F. C.; MIRO, V. H. A Tributação nas Vendas de Automóveis no Brasil: Quem Paga a Maior Parte da Conta? Economia (Brasília), Vol. 11, p. 559-596, 2010.

EXAME. Imposto náo é único culpado por carro mais de 100\% mais caro. 2013.

Disponível em: < http://exame.abril.com.br >. Acesso em: 11 de abr. 2015.

FARIAS, C. Poder de mercado no segmento de picapes pequenas da indústria automobilística brasileira. Tese de Doutorado, Universidade Federal de Viçosa. 2009.

FENABRAVE. Federação Nacional da Distribuição de Veículos Automotores.

Anuários estatísticos de 2001 a 2014. Disponível em: <http://www3.fenabrave.org.br >. Acesso em: 21 de jan. 2014.

GLOBO. Carros no Brasil custa bem mais caro que no exterior. 2009. Disponível em: < http:// g1.globo.com >. Acesso em: 11 de abr. 2015.

GOLLOP, F., ROBERTS, M. Firm interdependence in oligopolistic markets. Journal of Econometrics. Vol. 10, p. 313-331, 1979.

HALL, G. Overtime, effort, and the propagation of business cycle shocks. Journal of Monetary Economics. Vol. 38, p. 139-160, 1996.

HARRIS, D., MATYAS, L. Introduction to the Generalized Method of Moments Estimation em Generalized Method of Moments Estimation, ed. Laszlo Matyas, Cambridge University Press. p. 3-30, 1999.

HYDE, C., PERLOFF, J. Can market power be estimated? Review of Industrial Organization. Vol. 10, p. 465-485, 1995.

JACOB, K. G. Poder de mercado no segmento de automóveis até 1000 cilindradas: uma análise a partir da nova organização industrial empírica. 2015. 67 f. Dissertação (Mestrado em Economia) - Universidade Federal de Viçosa, 2015. 
JIN, YANGSOO. Testing Oil Refiners' Conduct in Korea: A Differentiated Product Approach. Asian Economic Journal, v. 28, n. 2, p. 161-180, 2014.

JUST, R., CHERN, W. Tomatoes, technology and oligopsony. Bell Journal of Economics. Vol. 11, p. 584-602, 1980.

LAGARIAS, J.C., REEDS, J. A., WRIGHT, M. H., WRIGHT, P. E. Convergence Properties of the Nelder-Mead Simplex Method in Low Dimensions. SIAM Journal of Optimization. Vol. 9, number 1, p. 112-147, 1998.

LAU, L. On identifying the degree of competitiveness from industry price and output data. Economics Letters. Vol. 10, p. 93-99, 1982.

LEE, C. SCP, NEIO and beyond. Nottinghan University Business School, Working Paper Series, 2007

MARTIN, S. Advanced industrial economics. Blackwell. 2002.

MATTOS, L. B., BARROS, A. M. Análise da estrutura do poder de mercado de carros populares, 1990-2005. Revista de Economia e Agronegócios. Vol 4, p. 365-386, 2006.

NEGRI, J. Elasticidade-renda e elasticidade-preço da demanda de automóveis no Brasil. IPEA. Texto para Discussão, n. 558, 1998.

PANZAR, J., ROSSE, J. Testing for monopoly equilibrium. Journal of Industrial Economics. Vol. 35, p. 443-456, 1987.

PETTERINI, F. C.; DESOUZA, S. A. Elasticidades e Markups no Mercado Brasileiro de Automóveis. Anais... 31º Encontro Brasileiro de Econometria, Foz do Iguaçu, 2009.

PIRES, L. S. Atos de concentração: uso do modelo ALM (Antitrust Logit Model) no setor de picapes médias. 2017. 100 f. Dissertação (Mestrado em Desenvolvimento Econômico) - Universidade Federal do Paraná, 2017.

PORTER, R. A study of cartel stability: the joint executive committee, 1880-1886. The Bell Journal of Economics. Vol. 14, p. 301-314, 1983.

RAPSON, D. Tacit collusion in the 1950s automobile industry? Revisiting Bresnahan (1987). Department of Economics, University of California. 2009.

RIVERS, D., VUONG, Q. Model selection tests for nonlinear dynamic models. Econometrics Journal. Vol. 5, p. 1-39, 2002.

ROTEMBERG, J., SALONER, G. A supergame-theoretic model of business cycles and price wars during booms. American Economic Review. Vol. 76, p. 390-407, 1986. 
SHEPHERD, W. G. The economics of industrial organization. New York: John Wiley \& Sons, 1997.

SOUZA, S. A.; RIBEIRO, E. P.; CARVALHO, G. Delimitaçáo de Mercado Relevante. Departamento de Estudos Econômicos (DEE), Grupo Técnico de Métodos em Economia (GTME), Brasília, 2010. Disponível em: <http://www.cade.gov.br>. Acesso em :16 dez. 2015.

STEEN, F., SALVANES, K. Testing for market power using a dynamic oligopoly model. International Journal of Industrial Organization. Vol. 17, p. 147-177, 1999.

SUDHIR, K. Competitive pricing behavior in the auto market: a structural analysis. Marketing Science. Vol. 20, p. 42-60, 2001.

WILDENBEEST, M. Structural Econometric Modeling in Industrial Organization Lecture. Indiana University, Kelley School of Business. 2016. Disponível em: <http:// kelley.iu.edu/mwildenb/teaching.html>. Acesso em: 17 de dez. 2015. 